\title{
Plasticity of the GABAergic Phenotype of the "Glutamatergic" Granule Cells of the Rat Dentate Gyrus
}

\author{
Rafael Gutiérrez, ${ }^{1}$ Héctor Romo-Parra, ${ }^{1}$ Jasmín Maqueda, ${ }^{1}$ Carmen Vivar, ${ }^{1}$ Mónica Ramírez, ${ }^{1}$ Miguel A. Morales, ${ }^{2}$ and \\ Mónica Lamas ${ }^{1}$ \\ ${ }^{1}$ Departamento de Fisiología, Biofísica y Neurociencias, Centro de Investigación y de Estudios Avanzados del Instituto Politécnico Nacional, Apartado \\ Postal 14-740, México 07000, and 2Instituto de Investigaciones Biomédicas, Universidad Nacional Autónoma de México, Apartado Postal 70228, Ciudad \\ Universitaria, México 04510
}

The "glutamatergic" granule cells of the dentate gyrus transiently express a GABAergic phenotype when a state of hyperexcitability is induced in the adult rat. Consequently, granule cell (GC) activation provokes monosynaptic GABAergic responses in their targets of area CA3. Because GABA exerts a trophic action on neonatal CA3 and mossy fibers (MF) constitute its main input, we hypothesized that the GABAergic phenotype of the MF could also be transiently expressed early in life. We addressed this possibility with a multidisciplinary approach. Electrophysiological recordings in developing rats revealed that, until day 22-23 of age, glutamate receptor antagonists block the excitatory response evoked in pyramidal cells by GCs, isolating a fast metabotropic glutamate receptor-sensitive GABAergic response. In a clear-cut manner from day 23-24 of age, GC activation in the presence of glutamatergic antagonists was unable to evoke synaptic responses in CA3. Immunohistological experiments showed the presence of $\mathrm{GABA}_{\mathrm{B}}$ and $\mathrm{GAD}_{67}$ (glutamate decarboxylase $67 \mathrm{kDa}$ isoform) in the developing GCs and their MF, and, using reverse transcription-PCR, we confirmed the expression of vesicular GABA transporter mRNA in the developing dentate gyrus and its downregulation in the adult. The GABAergic markers were upregulated and MF inhibitory transmission reappeared when hyperexcitability was induced in adult rats. Our data evidence for the first time a developmental and activity-dependent regulation of the complex phenotype of the GC. At early ages, the GABAergic input from the MF may add to the interneuronal input to CA3 to foster development, and, in the adult, it can possibly protect the system from enhanced excitability.

Key words: granule cells; mossy fibers; GABA; glutamate; development; plasticity; dentate gyrus; CA3

\section{Introduction}

During the first postnatal week, GABA exerts a depolarizing effect on CA3 hippocampal neurons, enabling NMDA receptors to activate (Leinekugel et al., 1997). From the second week, GABA exerts an inhibitory action (Gaiarsa et al., 1995; Ganguly et al., 2001), after which pyramidal cells reach adult features (Bayer, 1980). Thus, it has been proposed that the GABAergic input onto CA3 cells, thought to be originated in hilar and CA3 interneurons, exerts a trophic effect during development (Ben-Ari et al., 1994, 1997).

In the adult rat, the "normally glutamatergic" granule cells (GCs) of the dentate gyrus (DG) transiently express a GABAergic phenotype in an activity- and protein synthesis-dependent manner (Schwarzer and Sperk, 1995; Lehmann and Löscher, 1996; Sloviter et al., 1996; Lamas et al., 2001; Ramírez and Gutiérrez, 2001; Gómez-Lira et al., 2002; Gutiérrez, 2002), giving rise to GABAergic transmission from the mossy fibers (MFs) onto their

\footnotetext{
Received Dec. 10, 2002; revised April 7, 2003; accepted May 7, 2003.

This work was supported in part by Consejo Nacional de Ciencia y Tecnología Grant 36178-N and by the Third World Academy of Sciences Grant 01-401 (R.G.). M.L. was supported by the G-Fund.

Correspondence should be addressed to Rafael Gutiérrez, Departamento de Fisiología, Biofísica y Neurociencias Centro de Investigación y Estudios Avanzados del Instituto Politécnico Nacional, Apartado Postal 14-740, México 07000. E-mail: grafael@fisio.cinvestav.mx.

Copyright $\odot 2003$ Society for Neuroscience $\quad$ 0270-6474/03/235594-05\$15.00/0
}

targets in CA3 (Gutiérrez, 2000, 2002; Gutiérrez and Heinemann, 2001; Romo-Parra et al., 2003).

If as suggested, MFs release GABA besides glutamate, pyramidal cells could be driven by the MF-GABAergic signaling as well during development and could constitute an effective means to support the glutamate-GABA synergism on developing postsynaptic cells (Leinekugel et al., 1997). Therefore, we hypothesized that GCs could normally express their GABAergic phenotype during development, when GABA is needed to exert a trophic input to pyramidal cells adding to the GABAergic input of the hilar and CA3 interneurons. After completion of development, the expression of the GABAergic phenotype could be downregulated to establish the adult interneuron-mediated disynaptic inhibition onto CA3 targets. It is noteworthy that this possibility can also explain data showing that MF-GABAergic transmission is normally present in slices of young guinea pigs (Walker et al., 2001). We addressed this possibility and found that GABAergic markers are expressed in the GCs early in life, and MFGABAergic transmission is normally observed in rats until day $22-23$ of age. Strikingly, from this day on, activation of the GCs in the presence of glutamatergic antagonists no longer evokes synaptic responses in pyramidal cells while the GABAergic markers are downregulated. The induction of hyperexcitability reestablishes MF-GABAergic transmission and GABAergic markers expression. 
A

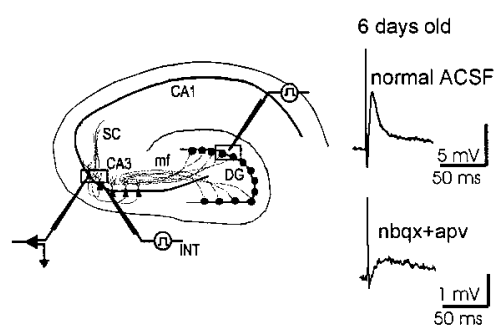

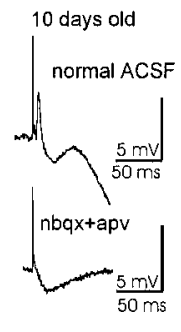

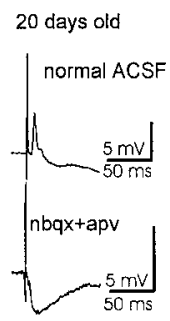

C

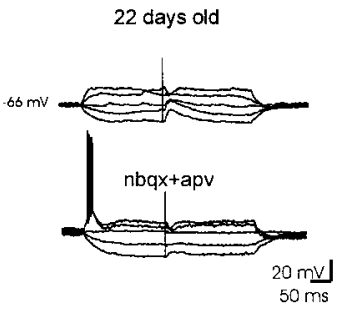

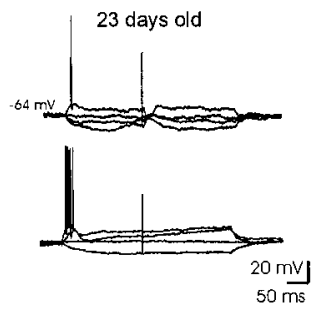

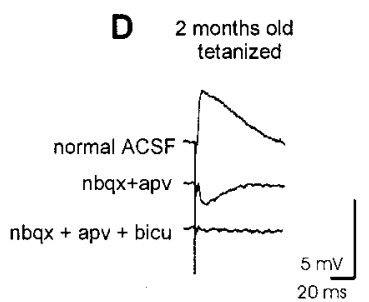

Figure 1. $A$, Sites of stimulation in the $D G$ and recording in $C A 3 C$. $B$, Synaptic responses of pyramidal cells to $D G$ activation at different ages before (normal ACSF) and after perfusion of NBQX plus APV show that MF-GABAergic transmission is transiently expressed during development. C, Synaptic responses evoked at different membrane potentials before and after NBQX plus APV show MF-GABAergic signaling at day 22 and its downregulation at day 23 of age. After this age, MF-GABAergic transmission is induced in an activity-dependent manner (D). Traces in $B$ and $D$ are an average of 10 responses.

\section{Materials and Methods}

We used Wistar rats of 6, 10, 15, 20, 22, 23, and $25 \mathrm{~d}$ and 1 and 2 months of age. Combined entorhinal cortex-hippocampus slices $(400 \mu \mathrm{m})$ were obtained and maintained at room temperature $\left(22^{\circ} \mathrm{C}\right)$ in oxygenated artificial CSF (ACSF) containing the following (mM): $124 \mathrm{NaCl}, 3 \mathrm{KCl}$, $1.25 \mathrm{NaH}_{2} \mathrm{PO}_{4}, 2 \mathrm{MgSO}_{4}, 2 \mathrm{CaCl}_{2}, 26 \mathrm{NaHCO}_{3}$, and 10 glucose, $\mathrm{pH}$ 7.35.

Electrophysiological experiments. After incubating the slices with ACSF at $35 \pm 0.5^{\circ} \mathrm{C}$ for $1 \mathrm{hr}$ in an air-liquid interface recording chamber, we recorded intracellular activity of pyramidal cells over area CA3a with glass microelectrodes (resistance, $60-80 \mathrm{M} \Omega$; filled with $2 \mathrm{M}$ potassium acetate) (Fig. $1^{1} \mathrm{~A}$ ). An AxoClamp 2B amplifier and pClamp8 software (Axon Instruments, Foster City, CA) were used for acquisition and analysis. For GC activation, single-pulse stimulation (duration of $0.1 \mathrm{msec}$ ) was delivered with a patch pipette ( $1 \mathrm{M} \Omega$, filled with ACSF) over the GC layer of the DG (Fig. 1A), at an intensity that evoked an EPSP with $60-70 \%$ of the amplitude required to make the cell fire action potentials. For interneuron activation, a patch pipette was placed $200-300 \mu \mathrm{m}$ away from the recording electrode over the limit of the strata pyramidale and lucidum. To induce MF-GABAergic transmission in adult preparations, three $1 \mathrm{sec}$ trains of $0.1 \mathrm{msec}$ pulses at $100 \mathrm{~Hz}$ (intertrain interval of 1 $\mathrm{min}$ ) were delivered every $15 \mathrm{~min}$ for $3 \mathrm{hr}$ over the perforant path at an intensity at which test pulses provoked $50 \%$ of maximal field potential amplitude in the DG (Gutiérrez, 2002).

The drugs used were diluted in the ACSF: the NMDA receptor antagonist (DL)-2-amino-5-phosphonovaleric acid (APV) (30 $\mu \mathrm{M}$; Tocris Cookson, Ballwin, MO); the non-NMDA receptor antagonist 6-nitro-7sulfamoylbenzo (f)quinolaxine- 2,3-dione (NBQX) (10 $\mu \mathrm{M}$; Tocris Cookson); the $\mathrm{GABA}_{\mathrm{A}}$ receptor antagonist bicuculline methiodide (20 $\mu \mathrm{M})$ (Sigma, St. Louis, MO); and the group III metabotropic glutamate receptor (mGluR) agonist $\mathrm{L}(+)$-2-amino-4-phosphonobutyric acid (LAP-4) (10 $\mu \mathrm{m}$; Tocris Cookson).

Immunohistological experiments. $\mathrm{GAD}_{67}$ (glutamate decarboxylase 67 $\mathrm{kDa}$ isoform) and GABA immunoreactivity (IR) was analyzed in hippocampal slices of four animals of each age group as mentioned above plus a group of $24 \mathrm{~d}$, as described previously (Ramírez and Gutiérrez, 2001). Briefly, slices were fixed in paraformaldehyde at $4 \%$ in PBS, cryoprotected in $30 \%$ sucrose, and then frozen and cut at 14 or $30 \mu \mathrm{m}$ in a cryostat at $-20^{\circ} \mathrm{C}$. They were incubated in the presence of rabbit $\mathrm{GAD}_{67}$ antibody (1:1000; Chemicon, Temecula, CA) and then in the presence of

25 days old

normal ACSF

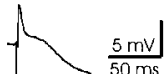

nbqx+apv

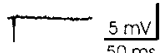

goat anti-rabbit IgG coupled to FITC (Vector FI-1000, 1:400; Vector Laboratories, Burlingame, CA). Detection of GABA-IR was done with a rabbit polyclonal antibody (Sigma; A2052; 1:1000 dilution) and a donkey biotynilated anti-rabbit IgG (RPN 1004; 1:300 dilution) and further incubated with FITCstreptavidin (Zymed 43-4311; 1:200 dilution; Zymed, San Francisco, CA). Selected sections were analyzed (usually 14 optical sections of 1 $\mu \mathrm{m})$ with a scanning confocal microscope (MRC 1024; Bio-Rad, Hercules, CA). Images were acquired with an excitation wavelength of 488 nm (Confocal Assistant; Tood Clark Brelje), and a densitometric analysis was conducted (Metamorph Imaging System; Universal Imaging Corporation, West Chester, PA) over two sites (CA3a and CA3b) of the stratum lucidum in four slices of each of three animals at $15,22,23,24$, and $30 \mathrm{~d}$ of age at high amplification $(60 \times)$. Immunofluorescence, expressed in arbitrary units of pixel gray values, was averaged per age group and scaled for graphical representation with a minimal and maximal relative value at 30 and $15 \mathrm{~d}$ of age, respectively. For control purposes, each experiment included a slice processed in the absence of the primary antibody.

Vesicular GABA transporter mRNA analysis. The semiquantitative determination of vesicular GABA transporter (VGAT) mRNA has been described previously (Lamas et al., 2001). In brief, it was analyzed by PCR coamplification with the endogenous internal standard gene hypoxanthine-guanine phosphoribosyltransferase (HPRT) from the granular cell layer of the DG dissected from two 500- $\mu$ m-thick hippocampal slices from each of three rats at 6,10 , and $15 \mathrm{~d}$ and 2 months of age. The primer set for VGAT was designed to amplify bases $471-1120$ of the rat coding sequence (McIntire et al., 1997). VGAT oligonucleotide primers were designed so as to bind to different exons allowing amplification products derived from cDNA and completely avoiding contaminating genomic DNA. The primer set that targets the constitutively expressed gene HPRT amplifies a $370 \mathrm{bp}$ PCR fragment. Samples of the different age groups were processed simultaneously and blindly analyzed by triplicate. The number of PCR cycles was fixed to yield a constant HPRT signal in all groups for each experiment. After PCR, the DNA products were electrophoresed on $1.2 \%$ agarose gels and stained with ethidium bromide. They were placed on a UV transilluminator and photographed with Polaroid-type 667 instant film. Photographs were subjected to densitometric analysis using LabWorks 4.0 software (UVP, Upland, CA).

\section{Results}

\section{Electrophysiological experiments}

In 6-d-old preparations, pyramidal cells responded to DG activation with a monophasic depolarizing potential, which was partially blocked by NBQX plus APV $(n=9)($ Fig. $1 B)$. The remaining depolarizing component could be blocked by bicuculline $(n=6)$ (Fig. 2A). From day 10 of age on, DG stimulation provoked depolarizing and hyperpolarizing postsynaptic potential sequences (EPSP/IPSP) (Fig. 1B). On perfusion of NBQX plus APV, the EPSP was completely blocked and a fast bicucullinesensitive IPSP was uncovered in all of the recorded cells from slices of 10-, 15-, and 20-d-old rats $(n=90)$ (Figs. $1 B, 2 A)$. The same responses were obtained in two electrophysiologically identified interneurons in a 10-d-old preparation (data not shown). The latencies of the pharmacologically isolated IPSPs for each age were not different from those of the corresponding control EPSPs. Thus, the mean latency difference of the EPSP and 


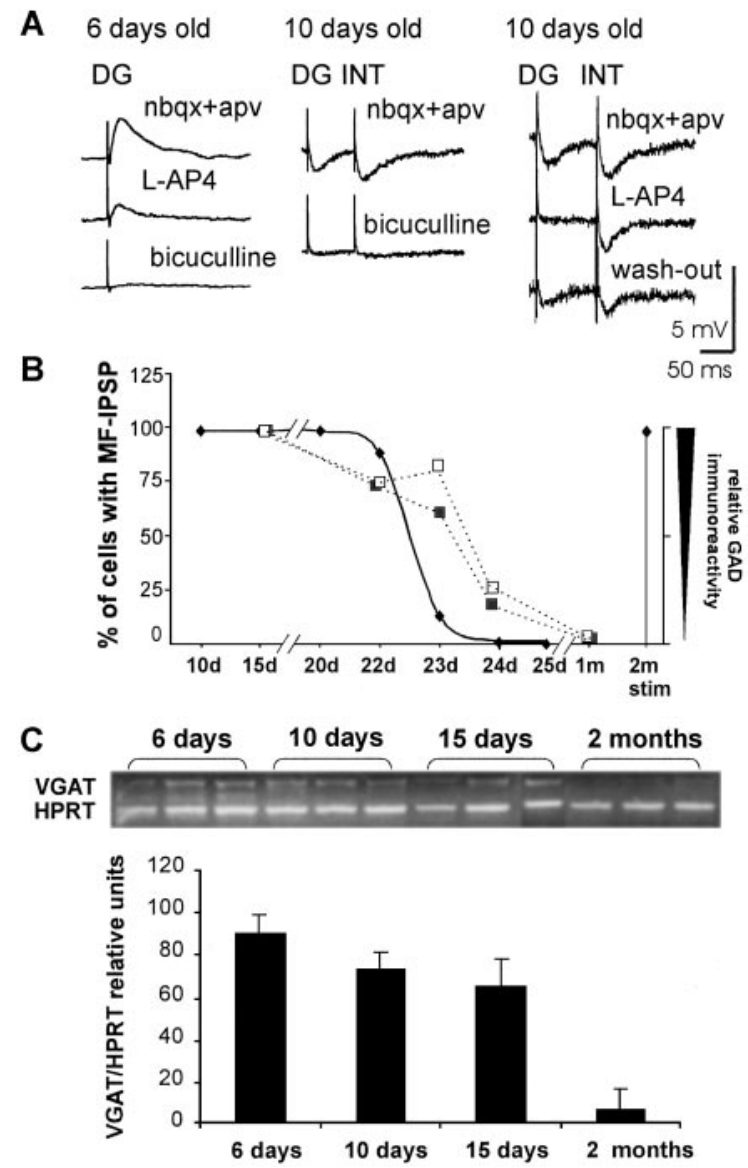

Figure 2. A, DG stimulation evokes bicuculline-sensitive monosynaptic depolarizing potentials at $6 \mathrm{~d}$ and hyperpolarizing responses at $10 \mathrm{~d}$ of age in pyramidal cells in the presence of NBQX plus APV. Contrary to responses of interneuronal (INT) origin, these responses are reversibly inhibited by L-AP-4. Traces are an average of 10 responses. B, Percentage of pyramidal cells that responded with a fast IPSP to DG activation in the presence of NBQX plus APV at different ages (rhombuses). In adults, MF-GABAergic transmission can be induced in an activitydependent manner (stim). $G \mathrm{D}_{67}$ immunoreactivity determined by densitometric analysis in CA3a (open squares) and in CA3b (filled squares) follows a similar trend. C, Expression of VGAT gene transcripts in the isolated DGs at the depicted ages. The bar graph shows the VGAT/HPRT ratio obtained from the whole series of experiments ( $n=3$ by triplicate), evidencing the expression of VGAT mRNA when MF-GABAergic transmission can be detected and its agedependent downregulation.

GABAergic potential $(0.13 \pm 0.08 \mathrm{msec})$ was consistent with a monosynaptic contact, as determined by a one-way ANOVA test and Scheffé post-ANOVA contrast $(6 \mathrm{~d}, F=1.1 ; 10 \mathrm{~d}, F=1.0$; $15 \mathrm{~d}, F=1.04 ; 20 \mathrm{~d}, F=1.4 ; 22 \mathrm{~d}, F=1.4 ; p<0.05)$. The reversal potential of the bicuculline-sensitive depolarizing potential determined at $6 \mathrm{~d}$ was $-46.5 \pm 5.1$ (mean resting membrane potential, $-69.6 \pm 1.8 \mathrm{mV} ; n=9$ ) and of the IPSPs in 10-, 15-, 20-, and 22 -d-old rats was $-68 \pm 1.6 \mathrm{mV}$ (mean resting membrane potential, $-64.5 \pm 1.2 \mathrm{mV} ; n=116$ ) (Fig. $1 C$ ). The rise time $(10-90 \%)$ of the control EPSP for each age was as follows (in msec): $6 \mathrm{~d}, 9.11 \pm 0.6 ; 10 \mathrm{~d}, 6.8 \pm 0.6 ; 15 \mathrm{~d}, 5.6 \pm 0.6 ; 20 \mathrm{~d}, 3.7 \pm$ $0.4 ; 22 \mathrm{~d}, 3.2 \pm 0.5 ; 23 \mathrm{~d}, 2.8 \pm 0.6$. The rise time of the isolated MF-evoked IPSP was as follows (in msec): $6 \mathrm{~d}, 10.4 \pm 1.3 ; 10 \mathrm{~d}$, $8.8 \pm 0.5 ; 15 \mathrm{~d}, 8.6 \pm 0.6 ; 20 \mathrm{~d}, 7.8 \pm 0.3 ; 22 \mathrm{~d}, 7.3 \pm 01$. The group III mGluR agonist L-AP-4, which selectively inhibits MFGABAergic transmission, reversibly depressed the DG-evoked depolarizing potential (6-d-old rats) and the IPSP (10- to 22-dold rats) by $83 \pm 4 \%$, whereas the IPSP evoked in the same cells by direct stimulation of interneurons within CA3 was unaffected $(n=47)$ (Fig. 2A).
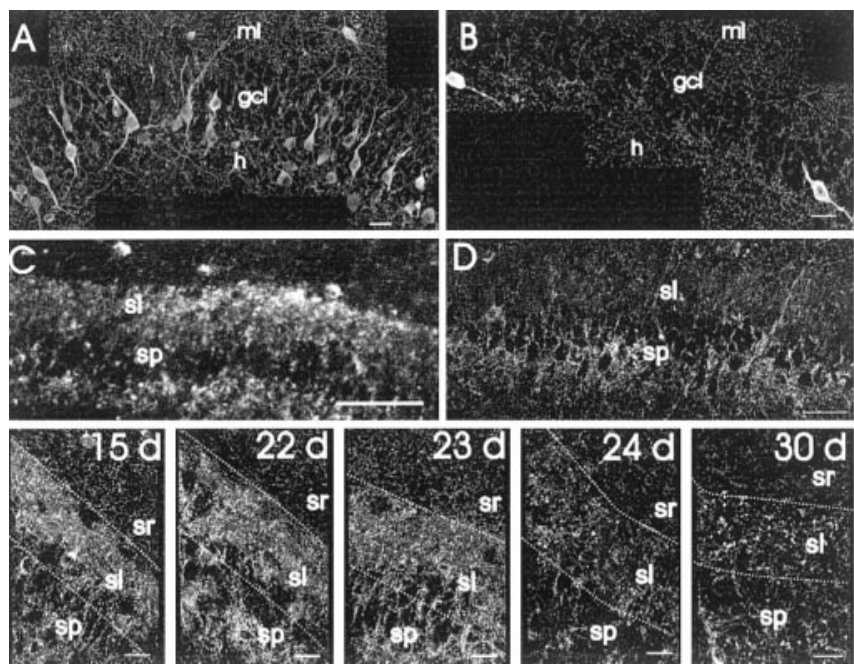

Figure 3. A, Confocal images show the presence of $G A B A$-immunoreactive interneurons and cells with characteristics of $\mathrm{GC}$ s within the stratum granulosum $(\mathrm{sg})$ of a 15-d-old preparation, whereas in adult preparations $(B)$, only interneurons are visible in the molecular layer $(\mathrm{ml})$ and in the border of the stratum granulosum and hilus $(h) . G A D_{67}-I R$ in the stratum lucidum (sl) of a 15-d-old ( $C$ and a 2-month-old ( D) preparation. The series of images below depicts $G_{A D}-I$ in $\mathrm{CA} 3 \mathrm{~b}$ at the indicated ages. These preparations were simultaneously processed. A clear downregulation is apparent toward the third week of life, when $G_{A D}-I R$ is restricted to terminals around pyramidal cells (sp) and to a few in the stratum lucidum and stratum radiatum (sr). Scale bars: $A, B$, lower array, $25 \mu \mathrm{m} ; C, D, 50 \mu \mathrm{m}$.

After $25 \mathrm{~d}$ of age, synaptic responses provoked by DG stimulation were completely blocked by NBQX plus APV $(n=150)$ (Fig. $1 B, C$ ). To determine the time at which the monosynaptic MF-GABAergic responses disappear, we recorded from 22- and 23 -d-old rats. At age 22 d, 26 of 29 cells, and at age 23 d, 4 of 30 cells responded with a monosynaptic IPSP to MF activation during glutamatergic blockade, indicating that this response shuts off in a clear-cut manner (Figs. $1 C, 2 B$ ). Because MF-GABAergic transmission can be induced in an activity-dependent manner in adult rats (Gutiérrez, 2002), we recorded from pyramidal cells of slices subjected to the induction protocol (see Materials and Methods) and corroborated that NBQX plus APV blocked the EPSP evoked by GC activation, isolating monosynaptic GABAergic responses in 30 of 30 cells tested (Fig. 1D).

\section{VGAT mRNA expression}

Because the activity-dependent expression of MF-GABAergic transmission correlated with that of VGAT mRNA in adult rats (Lamas et al., 2001), we explored its level of expression in the DG of developing rats. We found that, at the ages when MFGABAergic transmission is detected $(6,10$, and $15 \mathrm{~d})$, a steady expression of the VGAT mRNA was observed in all of the rats of each age group. In contrast, in the DG of young adult rats (2 months old), in which GABAergic transmission is not observed, VGAT mRNA is barely detected (Fig. 2C).

\section{Immunohistological experiments}

In slices of 6-, 10-, 15-, and 20-d-old rats, GABAimmunoreactive cells with characteristics of GCs were detected within the stratum granulosum of the DG (Fig. $3 A$ ). They had a round cell body, with a defined big nucleus and dendritic projections toward the stratum moleculare of the DG and the putative axonal projection toward the hilus. Although GABAimmunoreactive cells were detected along the whole extension of the stratum granulare, not all cells were GABA immunoreactive. 
Also, basket cells in the inner layer of the DG and interneurons in the hilar or molecular regions were apparent, which clearly differed in shape and orientation. In young adult rats, GABAimmunoreactive GCs were seldom detected, but interneurons in the hilus and stratum moleculare could be clearly observed (Fig. $3 B$ ). On the other hand, a clear $\mathrm{GAD}_{67}$-IR was observed in the MF of developing rats that progressively diminished with age (Figs. $2 B, 3)$. From approximately day $24-25, \mathrm{GAD}_{67}$-immunoreactive terminals were observed around pyramidal cells of CA3, but staining of the stratum lucidum was barely seen (Fig. 3D). The control slices that were processed in the absence of the primary antibody did not present immunoreactivity (data not shown).

\section{Discussion}

We show that the "normally glutamatergic" GCs transiently express a functional GABAergic phenotype during development and after the establishment of hyperexcitability in the adult. A low expression of $\mathrm{GAD}_{67}, \mathrm{GABA}$, and VGAT mRNA is normally found in GCs and their terminals (Sandler and Smith, 1991; Sloviter et al., 1996; Lamas et al., 2001), and seizures (Schwarzer and Sperk., 1995; Lehmann et al., 1996; Sloviter et al., 1996; Lamas et al., 2001; Gómez-Lira et al., 2002) or LTP-like stimulation (Lamas et al., 2001; Ramírez and Gutiérrez, 2001) upregulate their expression. Accordingly, activity- and protein synthesisdependent induction of monosynaptic MF-GABAergic signaling onto CA3 is observed (Gutiérrez, 2000, 2002; Gutiérrez and Heinemann, 2001; Gutiérrez, 2002; Romo-Parra et al., 2003). Also, in agreement with the idea that GCs release GABA, Walker et al. (2001) showed monosynaptic MF-GABAergic transmission to be normally present in slices from young guinea pigs. These results, however, were in conflict with our previous results in that no activity-dependent mechanisms seem to be involved in MFGABAergic transmission. With our present evidence, we show that the developmental stage is the determining factor underlying these apparent conflicting results and establish that developmental and activity-dependent mechanisms underlie this phenomenon.

Our electrophysiological evidence demonstrates that fast mGluR-sensitive GABAergic transmission can be evoked in CA3 by MF activation at early ages. On day 6 of age, MF activation evokes an NBQX plus APV-insensitive depolarizing response that can be blocked by bicuculline and whose reversal potential coincides with GABAergic responses at this age (Ganguly et al., 2001). Thereafter, MF activation provokes hyperpolarizing GABAergic responses that disappear in a clear-cut manner on day 23-24 of age. Both the early depolarizing and hyperpolarizing MF-GABAergic potentials are strongly inhibited by the type III mGluR agonist L-AP-4, which presynaptically inhibits MFGABAergic transmission (Gutiérrez, 2000, 2002; Walker et al., 2001; Romo-Parra et al., 2003). This is a reliable test to identify neurotransmission of MF origin because these receptors are located in MF terminals (Ohishi et al., 1995). On the other hand, GABAergic responses of interneuronal origin are not affected by mGluR activation (Walker et al., 2001; Romo-Parra et al., 2003). Additional investigation is needed to establish whether glutamate and GABA are released from the same MF terminal and how the proportion of release of both amino acids varies during development.

The release of GABA from MF in the developing rat has possibly been observed (Ben-Ari et al., 1989) but not identified as such. In developing rats, giant synchronous discharges appear that are primarily mediated by $\mathrm{GABA}_{\mathrm{A}}$ receptors and by MF synaptic input. Interestingly, the selective lesion of the DG blocks most of the excitatory drive to these cells (Henze et al., 1997), suggesting that MF-GABAergic input can be disrupted. Activation of GABA and glutamate receptors happens in synergy in developing rats, because a strong excitatory drive is needed to activate NMDA receptors (Leinekugel et al., 1997). Therefore, it is tempting to speculate that MF-GABAergic transmission possibly contributes to the development of CA3 neurons. Interestingly, the clear-cut shut off of MF-GABAergic responses happens on day 22-23, 2 weeks after GABA has ceased to exert depolarizing actions. This suggests that MF-GABAergic transmission accompanies the morphological maturation of pyramidal cells possibly until the completion of the development of dendrites and spines, which happens at approximately the same time (Ben-Ari, 2001).

In direct correspondence, VGAT mRNA is expressed in the DG of young animals but barely detected when MF-GABAergic transmission is no longer observed. However, MF-GABAergic transmission reappears when hyperexcitability is induced and VGAT mRNA expression is, therefore, upregulated (Lamas et al., 2001). Also, contrary to adult preparations, GABAimmunoreactive putative GCs are detected in the $\mathrm{DG}$, and $\mathrm{GAD}_{67}$ is clearly observed in the MF of young animals. In our analysis, although some GABA-immunoreactive cells are likely to be basket cells (Ribak and Seress, 1983, 1988), some cells with typical features of GCs are GABA immunoreactive. Granule cells originated at different postnatal ages coexist (Gaarskjaer, 1985), and it seems probable that the younger GCs in the adult, which lie in the inner portion of the GC layer in the developing rat (Altman and Bayer, 1990), are those that express GABAergic markers. It is suggestive that MF innervation of CA3 neurons seems to be more abundant during development and MF extensions are longer by day 14 than in the mature animal (Amaral and Dent, 1981). This could explain why not all GCs need to express GABA. More indicative for the GABAergic phenotype of the MF pathway was its clear $\mathrm{GAD}_{67}$-IR observed in the young animals and its downregulation at approximately the same time when DG-to-CA3 disynaptic inhibition is established. Dupuy and Houser (1996) have shown a shift in the intracellular distribution of $\mathrm{GAD}_{67}$ from cell bodies to terminal-like structures at late prenatal to early postnatal ages and have suggested that the $\mathrm{GAD}_{67}$-containing terminallike structures identified early in life, adjacent to the pyramidal layer in CA3, are likely to be the source of GABA for developmental functions. Finally, for MF-GABAergic transmission to occur, $\mathrm{GABA}_{\mathrm{A}}$ receptors must be in the subsynaptic site. Interestingly, in cultured pyramidal cells, $\mathrm{GABA}_{\mathrm{A}}$ receptors cluster apposed to glutamatergic presynaptic elements, suggesting the hypothesis that there is an element common to GABA and glutamate synapses (Rao et al., 2000). It is therefore likely that pyramidal cells do normally have GABA receptors in apposition to MF inputs, which explains why fast MF-GABAergic synaptic responses can be normally seen in the developing rat and induced in the adult.

The developmental plasticity of MF-GABAergic transmission that we have evidenced reflects the suggested transient expression of the GABAergic phenotype of cells within the DG at early ages (Dupuy and Houser, 1996, 1997). This, together with data showing a sequential formation of functional $\mathrm{GABA}_{\mathrm{A}}$ and glutamatergic synapses (Hennou et al., 2002), put our data in a developmentally relevant perspective. We propose that the complex expression of GC phenotype contributes to developmental and protective functions. This idea has received increasing support and proves that the phenotypic plasticity is put in play in response to environmental influences (Cao et al., 1996). The enhanced excitability of a GABA-releasing MF pathway goes in line with the 
protection of principal cells in the hippocampus (Holmes et al., 1999; Haas et al., 2001) and hilar neurons of young animals (Ribak and Navetta, 1994), which in general are less prone to the deleterious effects of seizures.

\section{References}

Altman J, Bayer SA (1990) Migration and distribution of two populations of hippocampal granule cell precursors during the perinatal and postnatal periods. J Comp Neurol 301:365-381.

Amaral DG, Dent JA (1981) Development of the mossy fibers of the dentate gyrus. I. A light and electron microscopic study of the mossy fibers and their expansions. J Comp Neurol 195:51-86.

Bayer SA (1980) Development of the hippocampal region in the rat. II. Morphogenesis during embryonic and early postnatal life. J Comp Neurol 190:115-134.

Ben-Ari Y (2001) Developing networks play a similar melody. Trends Neurosci 24:353-360.

Ben-Ari Y, Cherubini E, Corradetti R, Gaiarsa JL (1989) Giant synaptic potentials in immature rat CA3 hippocampal neurones. J Physiol (Lond) 416:303-325.

Ben-Ari Y, Tseeb V, Raggozzino D, Khazipov R, Gaiarsa JL (1994) gammaAminobutyric acid (GABA): a fast excitatory transmitter which may regulate the development of hippocampal neurones in early postnatal life. Prog Brain Res 102:261-273.

Ben-Ari Y, Khazipov R, Leinekugel X, Caillard O, Gaiarsa JL (1997) GABAA, NMDA and AMPA receptors: a developmentally regulated "ménage a trois." Trends Neurosci 20:523-529.

Cao Y, Wilcox KS, Martin CE, Tachinsky TL, Eberwine J, Dichter MA (1996) Presence of mRNA for glutamic acid decarboxylase in both excitatory and inhibitory neurons. Proc Natl Acad Sci USA 93:9844-9849.

Dupuy ST, Houser CR (1996) Prominent expression of two forms of glutamate decarboxylase in the embryonic and early postnatal rat hippocampal formation. J Neurosci 16:6919-6932.

Dupuy ST, Houser CR (1997) Developmental changes in GABA neurons of the rat dentate gyrus: an in situ hybridization and birthdating study. J Comp Neurol 389:402-418.

Gaarskjaer FB (1985) The development of the dentate area and the hippocampal mossy fiber projection of the rat. J Comp Neurol 241:154-170.

Gaiarsa JL, McLean H, Congar P, Leinekugel X, Khazipov R, Tseeb V, Ben-Ari Y (1995) Postnatal maturation of gamma-aminobutyric acid-A and B-mediated inhibition in the CA3 hippocampal region of the rat. J Neurobiol 26:339-349.

Ganguly K, Schinder AF, Wong ST, Poo M (2001) GABA itself promotes the developmental switch of neuronal GABAergic responses from excitation to inhibition. Cell 105:521-532.

Gómez-Lira G, Trillo E, Ramírez M, Asai M, Sitges M, Gutiérrez R (2002) Expression of GABAergic transmission in the mossy fiber synapse coincides with the seizure-induced expression of GABA in mossy fiber synaptosomes. Exp Neurol 177:276-283.

Gutiérrez R (2000) Seizures induce simultaneous GABAergic and glutamatergic neurotransmission in the dentate gyrus-CA3 system. J Neurophysiol 84:3088-3090.

Gutiérrez R (2002) Activity-dependent expression of simultaneous glutamatergic and GABAergic neurotransmission from the mossy fibers in vitro. J Neurophysiol 87:2562-2570.

Gutiérrez R, Heinemann U (2001) Kindling induces transient fast inhibition in the dentate gyrus-CA3 projection. Eur J Neurosci 13:1371-1379.

Haas KZ, Sperber EF, Opanashuk LA, Stanton PK, Moshe SL (2001) Resistance of immature hippocampus to morphologic and physiologic alter- ations following status epilepticus or kindling. Hippocampus 11:615-625.

Hennou S, Khalilov I, Diabira D, Ben-Ari Y, Gozlan H (2002) Early sequential formation of functional GABAA and glutamatergic synapses on CA1 interneurons of the rat foetal hippocampus. Eur J Neurosci 6:197-208.

Henze DA, Card JP, Barrionuevo G, Ben-Ari Y (1997) Large amplitude miniature excitatory postsynaptic currents in hippocampal CA3 pyramidal neurons are of mossy fiber origin. J Neurophysiol 77:1075-1086.

Holmes GL, Sarkisian M, Ben-Ari Y, Chevassus-Au-Louis N (1999) Mossy fiber sprouting after recurrent seizures during early development in rats. J Comp Neurol 404:537-553.

Lamas M, Gómez-Lira G, Gutiérrez R (2001) Vesicular GABA transporter mRNA expression in the dentate gyrus and in mossy fiber synaptosomes. Mol Brain Res 93:209-214

Lehmann H, Ebert U, Löscher W (1996) Immunocytochemical localization of GABA immunoreactivity in dentate granule cells of normal and kindled rats. Neurosci Lett 212:41-44.

Leinekugel X, Medina I, Khalilov I, Ben-Ari Y, Khazipov R (1997) $\mathrm{Ca}^{2+}$ oscillations mediated by the synergistic excitatory actions of GABA(A) and NMDA receptors in the neonatal hippocampus. Neuron 18:243-255.

McIntire SL, Reimer RJ, Schuske K, Edwards RH, Jorgensen EM (1997) Identification and characterization of the vesicular GABA transporter. Nature 389:870-876

Ohishi H, Akazawa C, Shigemoto R, Nakanishi S, Mizuno N (1995) Distributions of the mRNAs for L-2-amino-4-phosphonobutyrate-sensitive metabotropic glutamate receptors, mGluR4 and mGluR7, in the rat brain. J Comp Neurol 360:555-570.

Ramírez M, Gutiérrez R (2001) Activity-dependent expression of GAD67 in the granule cells of the rat hippocampus. Brain Res 917:139-146.

Rao A, Cha EM, Craig AM (2000) Mismatched appositions of presynaptic and postsynaptic components in isolated hippocampal neurons. J Neurosci 20:8344-8353.

Ribak CE, Navetta MS (1994) An immature mossy fiber innervation of hilar neurons may explain their resistance to kainite-induced cell death in 15day-old rats. Dev Brain Res 79:47-62.

Ribak CE, Seress L (1983) Five types of basket cells in the hippocampal dentate gyrus: a combined Golgi and electron microscopic study. J Neurocytol 12:577-597.

Ribak CE, Seress L (1988) The development of GABAergic neurons in the rat hippocampal formation. An immunocytochemical study. Dev Brain Res 44:197-209.

Romo-Parra H, Vivar C, Maqueda J, Morales MA, Gutiérrez R (2003) Activity-dependent induction of multitransmitter signaling onto pyramidal cells and interneurons of hippocampal area CA3. J Neurophysiol 89:3155-3167.

Sandler R, Smith AD (1991) Coexistence of GABA and glutamate in mossy fiber terminals of the primate hippocampus: an ultrastructural study. J Comp Neurol 303:177-192.

Schwarzer C, Sperk G (1995) Hippocampal granule cells express glutamic acid decarboxylase 67 after limbic seizure in the rat. Neuroscience 69:705-709.

Sloviter RS, Dichter MA, Rachinsky TL, Dean E, Goodman JH, Sollas AL, Martin DL (1996) Basal expression and induction of glutamate decarboxylase and GABA in excitatory granule cells of the rat and monkey hippocampal dentate gyrus. J Comp Neurol 373:593-618.

Walker MC, Ruiz A, Kullmann DM (2001) Monosynaptic GABAergic signaling from dentate to CA3 with a pharmacological and physiological profile typical of mossy fiber synapses. Neuron 29:703-715. 